\title{
CARCINOMA EPIDERMÓIDE
}

Heitor Busatto PEREIRA, Marco Aurélio Ferreira LUIZ, Thiago Ferreira LUIZ, Vanessa VELTRINI

O carcinoma epidermóide representa 90 a 95\% das neoplasias malignas da boca, localizando-se principalmente na língua. Acomete, em geral, homens com idade acima de 60 anos, a maioria com história de alto consumo de tabaco e álcool. Esta patologia raramente ocorre em pacientes com menos de 40 anos, quando a real influência de fatores carcinogênicos é bastante discutida. Alguns autores argumentam que essas substâncias, reconhecidamente carcinogênicas em pacientes mais velhos, também poderiam estar relacionadas ao aparecimento de carcinomas epidermóides em pacientes mais jovens. Outros, entretanto, relatam que muitos desses pacientes nunca fumaram ou ingeriram bebida alcoólica, ou ainda, que o tempo de exposição a esses agentes seria muito curto para induzir a transformação maligna. Neste contexto, paciente J.D.V., 53 anos, gênero masculino, caucasiano, apresentou-se à clínica de estomatologia do Cesumar com uma lesão ulcerada, formato irregular, consistência firme, superfície rugosa e limites indefinidos, localizada no soalho bucal, com sintomatologia dolorosa e tempo de evolução de aproximadamente 3 anos, sendo que o paciente em questão fumou 1,5 maços de cigarro ao dia por 20 anos, e consumia bebidas alcoólicas há 25 anos, o que ajudou a explicar a ocorrência da neoplasia neste paciente. 